\title{
Mathematics Curriculum Review by Advancing the Use of Learning Design Map and Subjects Classification
}

\author{
1Maman Fathurrohman, ${ }^{2}$ Anne L. Porter, ${ }^{2}$ Annette L Worthy, ${ }^{3}$ Rosni Abdullah, \\ ${ }^{4}$ Supriyanto, ${ }^{1}$ Aan Subhan Pamungkas \\ ${ }^{1}$ Department of Mathematics Education, Universitas Sultan Ageng Tirtayasa, Serang, Indonesia \\ ${ }^{2}$ School of Mathematics and Applied Statistics, University of Wollongong, Wollongong, Australia \\ ${ }^{3}$ School of Computer Sciences, Universiti Sains Malaysia, Penang, Malaysia \\ ${ }^{4}$ Department of Electrical Engineering, Universitas Sultan Ageng Tirtayasa, Serang, Indonesia \\ e-mail: mamanf@untirta.ac.id
}

\begin{abstract}
Curriculum review is a long process. Typically, the people responsible for these activities are one or two people (coordinators) who are responsible for this and it can be burdensome. Authors propose a new computer-based method for mathematics curriculum review by advancing the use of Learning Designs Maps (LDMaps). The LDMaps have already been developed by authors to document expected mathematics teaching and learning experiences as expected by the curriculum. The proposed method can disperse the process allowing the responsible coordinators to conduct the simple task of collating available LDMaps for the review. In this paper, an example of a mathematics curriculum review in counting mathematics subjects classification entries is presented.
\end{abstract}

Keywords: Mathematics Curriculum, Curriculum Review, Learning Design Map, Mathematics Subjects' Classification

How to Cite: Fathurrohman, M., Porter, A.L., Worthy A.L., Abdullah, R., Supriyanto, \& Pamungkas A.S. (2019). Mathematics Curriculum Review by Advancing the Use of Learning Design Map and Subjects Classification. International Journal on Emerging Mathematics Education, 3(1), 27-40. http://dx.doi.org/10.12928/ijeme.v3i1.11929

\section{INTRODUCTION}

There are fundamental differences between people's conceptions of curriculum, focusing on curriculum as reality in teaching and learning in the class and curriculum as a plan for or a report of actual educational events. Kallick \& Colomo (2009) proposed that there are often differences between the written curriculum and the taught curriculum.

In this paper, the curriculum is defined as the list of subjects, comprising a formal course of study that states the resource and the design of learning in order to achieve the purpose of curriculum stated by an institution. This perspective of the written curriculum is chosen because the research deals with the written curriculum documents or the teaching that is expected. In addition to this definition, by regarding the total curriculum, the design of the curriculum must be defined by a school or college in which the curriculum will be implemented. The curriculum has an impact on teaching and learning, such as shown by Naseer (2018). For that reason, the curriculum must be reviewed. The review of the curriculum is a long process. Typically the people responsible for these activities are one or two people (coordinators) who are responsible for this and it can be burdensome. It is noted that computer-based support would be helpful for curriculum analysis, design, and evaluation (McKenney, 
2008). As Lee (2010) advocates, mathematics curriculum design, in some way, curriculum review is an important part of it. In addition to this, the content of the curriculum, such as mathematics realistic themes, in mathematics curriculum, as advocated by Revina and Leung (2018), also may contribute to curriculum mapping.

Curriculum needs to be reviewed or evaluated to make it appropriate given current conditions and the development of the institution, as also explained by the seminal paper by Dressel (1965) about the importance of curriculum review. Davis (1981) in his seminal book Teachers as Curriculum Evaluators also emphasize that teachers are the main participants in the review or evaluation of curriculum. Based on this view, teachers or the persons who conduct teaching and learning of subjects formally listed in the curriculum, should be empowered to participate in the process of curriculum review.

Curriculum mapping as the way to conduct curriculum review can be conducted using Learning Design Map (LDMap), a technology developed to document the expected mathematical teaching and learning experiences (Fathurrohman, Porter, Worthy, 2012). A responsible educator for the course, maps the learning designs for each formal subject, resulting in a set of files. These maps contain data regarding expectations of what is to be taught, in their class, and will be usable as a tool to document teacher knowledge and curriculum materials, since this file is expected to be created by educators and to be shared among them. The existence of LDMap as evidence of expected mathematics teaching and learning based on curriculum may contribute to the increasing quality of instruction in mathematics teaching and learning, to support Hill and Charalambous (2012) exploration on variations of teachers' Mathematical Knowledge for Teaching (MKT) and Curriculum Materials to achieve high-quality instruction.

Additional technology tools to draw together the individual learning design maps to provide an overall mapping of the curriculum in terms of content or competencies required and the development of this is discussed in the next section. By taking advantage of LDMaps' characteristics and ability to document learning designs data such as the assessment tasks set and the graduate attributes, the learning design data of each subject can be aggregated and displayed for review purposes.

\section{RESEARCH METHOD}

One crucial component of this research involves a mixture of data gathering techniques as it relates to the design and development of software tools. Design and development research can be defined as the systematic study of design, development, and evaluation processes with the aim of establishing an empirical basis for the creation of instructional and non-instructional tools and new or enhanced models that govern their development (Ross, Morrison, Hannafin, Young, et al, 2008). Furthermore, the authors also stated that this research is closely related to mixed methods such as design and development research tends to be complex methodologically. This is typical because of the complexities of real-life situations and of the design and development process themselves. This research tends to employ either mixed-method or multiple method approaches (Ross, Morrison, Hannafin, Young, et al, 2008)

A series of activities were undertaken to identify 1) What was required of a curriculum review, in one specific instance, a partial curriculum review of a mathematics degree at the University of Wollongong (UOW), Australia; 2) Examination of existing review software in terms of functionality; 3) Extension of the LDSoft mapping tools through development of additional curriculum review tools to enable

IJEME, Vol. 3, No. 1, March 2019, 27-40. 
the use of LDMaps in curriculum review; 4) Staff Interview to assess their needs and advices in relation to curriculum mapping; 5) Extending the use of the proposed method.

\section{RESULTS AND DISCUSSION}

As the target group for this work expanded to encompass both schools and universities, the term educator is used to refer to school teachers and/or university lecturers, while the term unit refers to an educational institution which uses or develops their own curriculum, such as a school or department. The process of curriculum review in this paper is focused on the mathematics discipline but could be extended to other disciplines.

\section{Mathematics Curriculum Review}

An example of a mathematics curriculum of partner university is used for the purpose of this research. The Bachelor of Mathematics degree curriculum, at the time of research, at University of Wollongong (UOW) consists of 30 subjects that spread throughout four subject levels of 100-level, 200-level, 300-level, and 400-level. Each level has different course requirements and difficulty for completion. The subjects consist of $6(20 \%)$ of 100 -level courses, $8(26.7 \%)$ of 200 -level courses, $14(46.7 \%)$ of 300 -level courses, and $2(6.7 \%)$ of 400 -level courses. To complete the study for a Bachelor of Mathematics degree, a student is required to satisfactorily complete at least 144 credit points which must include eight core subjects.

\section{Software for curriculum review}

Many curriculum mapping software tools have been developed in order to facilitate educators in conducting curriculum mapping. Examples of such software are presented in Table 1.

Table 1. List of existing curriculum related software

\begin{tabular}{|c|c|c|c|}
\hline No & Software & Feature(s) & Review \\
\hline 1 & $\begin{array}{l}\text { Rubicon Atlas } \\
\text { Curriculum } \\
\text { Mapping by } \\
\text { Rubicon } \\
\text { International } \\
\text { (Commercial) }\end{array}$ & 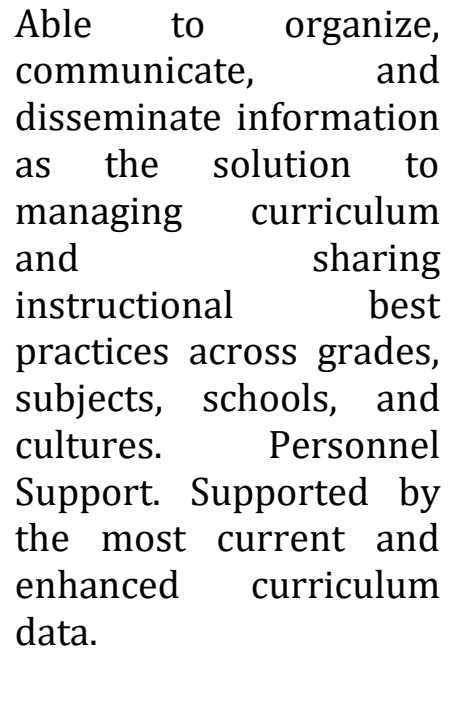 & $\begin{array}{l}\text { Atlas is a Web application designed to } \\
\text { electronically encompass the process } \\
\text { of curriculum mapping to facilitate } \\
\text { collaboration among teachers across } \\
\text { subjects, grades, and schools. Atlas } \\
\text { probably the first and well-known } \\
\text { educational software focused in } \\
\text { curriculum mapping. Rubicon, the } \\
\text { owner of Atlas provides training to } \\
\text { teachers on how to use and } \\
\text { implement this software. According } \\
\text { to its users, Atlas is easy to use, } \\
\text { useful, productive mapping software, } \\
\text { and has a good and helpful technical } \\
\text { support. }\end{array}$ \\
\hline 2 & $\begin{array}{l}\text { Agile Minds } \\
\text { Curriculum } \\
\text { Mapping and } \\
\text { Design by } \\
\end{array}$ & $\begin{array}{l}\text { Able to design and map } \\
\text { the curriculum. } \\
\text { Familiarity with the } \\
\text { Australian curriculum. }\end{array}$ & $\begin{array}{l}\text { The curriculum mapping tool is } \\
\text { provided by an Australian curriculum } \\
\text { consultant who has expertise in } \\
\text { mapping the Australian curriculum. }\end{array}$ \\
\hline
\end{tabular}




\section{Australian}

Curriculum

Consultant

(Commercial)

3 Excel-based

Curriculum

Review by

Curtin

University

(Private ownership)

4 Curriculum Mapping

Tools by

Faculty of

Commerce

UOW (Private

ownership)

5 TODCM

Curriculum

Mapping by

Tiller

Software

Company

(Open

Source)

6 Curriculum

Mapper by

Collaborative

Learning, Inc

(Commercial)

7 Tech Paths by

Performance

Pathways

(Commercial)
Able to analyze course data automatically by typing or pasting data to the excel cell provided in this tool.

Web-based curriculum mapping. Integrated information about graduate qualities. Data and information can be exported to excel files to be analyzed later. Mapping Software. Customizable. Real-time PDF generation
Web-based Curriculum

This software is not as popular as Rubicon Atlas

This is a research-based curriculum mapping tool. This tool is currently well-known in Australia. This software requires skilled users for purposes of modification.

This software is being been developed and is currently being trialed in the Faculty of Commerce, UOW. This software is web-based software.

TODCM is a software framework that helps schools and organizations to implement a curriculum mapping tool according to their own specific requirements. TODCM already implemented in four international schools: TODCM is based on the user interface concept of the Zurich Mapping System (ZMS) developed by Greg Curtis

Simple interface to align curriculum, share best practices, and create a variety of custom reports for both administrators and teachers

Search and share features provided to enhance collaborations among teachers when developing maps.
8 Curricu PLAN by Seacliff Education Solution
Web-based curriculum mapping. Provides online access for educators to participate
The Curriculum Mapper is a webbased mapping system developed by classroom teachers and administrators. It allows teachers to easily input curricular data as well as attach lesson plans, rubrics, to any part of their maps

A Curriculum Mapping System. Data entry of curriculum map elements contains essential questions, content, skills, assessments, and lessons. The information entered by teachers provides numerous reports to aid administrators in understanding the curriculum as implemented by teachers in their schools and District as they attempt to align to standards.

Curricu PLAN is a web-based curriculum mapping and instructional content management solution that provides online access 
(Commercial) in an online community.

9 Moodle (Open source, some aspects are commercial)
Additional capability of course management system for use in curriculum mapping. for educators to participate in an online community focused on the development of high-quality instruction with the common goal of increasing student achievement.

Moodle is originally purposed as a Course Management System (CMS), also known as a Learning Management System (LMS), however, curriculum mapping features can be implemented through a Moodle platform.

The ability to adapt the LDMaps for the purposes of curriculum review was based on the ability for the learning design data in the LDMaps to be captured and reused and connected to other applications. In mapping the curriculum, one needs to identify the core subjects that all students must complete in order to achieve a given degree. At the UOW, core subjects need to encompass all learning outcomes or graduate attributes that are required, as there is no guarantee that all students complete the elective subjects.

\section{Advancing the Use of Learning Design Map}

Participations of lecturers in the review process is expected to disperse the process, allowing the responsible coordinators or staff to easily and automatically conduct simple task of collating available LDMaps. Assuming, and this is not currently the case, that LDMaps were created for each core subject in the Bachelor of Mathematics degree, then there would be at least eight LDMaps available in the unit. Decisions would need to be made in relation to whether or not to include all alternative core subjects. The mathematics curriculum can be reviewed based on data contained in LDMaps associated with subjects in this degree. To ensure that data are available for aggregation prospectively, the data needs to be captured prospectively through existing processes.

To undertake a review of mathematics subjects at the University of Wollongong two main needs were identified and this required the collection of additional data to that collected in the Learning Design Maps (LDMaps). First, graduate qualities that were to be aligned with the tasks or assessment of the subject per week. Second, Mathematics Subject Classifications (MSC), a unique feature of mathematics in which mathematics-related literature can be indexed by topic, and subsequently aligned with mathematical learning resources provided in the subject each week.

The Mathematics Subject Classification is produced by the editorial staff of Mathematical Reviews and Zentralblatt fur Mathematik (Zbl) in consultation with the mathematical community. The list consists of 63 first level classifications started from 00: General to 97: Mathematics Education. The second level of classification is also available. This classification can be used to get specific or detail information about the subtopics. The use of the second level, at this time this remains to be developed and when implemented will result in the second list of classifications to be selected in conjunction with the main topic selected by lecturers completing the LDForm. The concept as presented was implemented in a simple modified excel-based form, called Learning Design Forms (LDforms). 
To analyze the data contained in LDMaps, an additional tool to automatically analyze these maps, Curriculum Reviewer, was required. Like the LDForm, this tool was designed and developed based on Microsoft Excel. The tool, called Learning Designs-based Curriculum Reviewer (LDCR), can be used to import the data from all LDMaps of the required subjects for use in the curriculum review. The analysis of the data contained in these files can be done automatically. A review of all subjects could be used for self-reflection on the current mathematics curriculum or to document for external accreditation bodies that the graduate attributes were met (see in Figure 1).

Demonstrations of the use of the curriculum tools will be based on two selected mathematics subjects from the School of Mathematics and Applied Statistics, University of Wollongong. Discrete Mathematics (MATH121) and Mathematics for Primary Educators (MATH131) were selected as the example for this purpose. This partial review will focus on the process for reviewing such as subject information, mathematical learning resources, topics taught as classified with the Mathematics Subjects Classification, distribution of expected graduate qualities; and subjects' assessments.

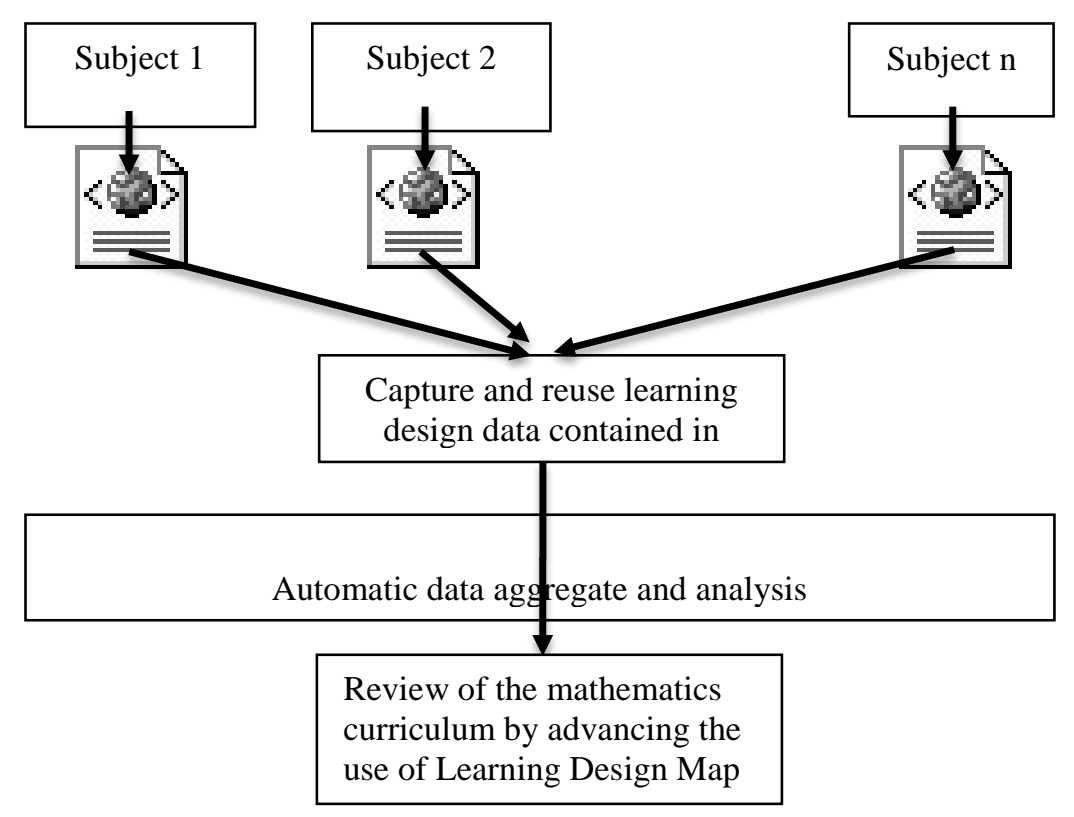

Figure 1. The concept for advancing the use of learning design map

Figure 2 shows how data flow from one form to others. Currently, the form is still Excel-based, but later can be developed in web-based or another sophisticated form. The flow of data (including learning design data) is from the front page section

to the remaining sections, which finally results in an LDMap. The lecturer or subject coordinator is required to complete the first (frontpage form) and the second/third page of the form (first/second half-semester form). The data collected in these forms can then be used to generate the basic information in the Subject Information Sheet that can then be modified or added to if required by the lecturer. At the same time the data entered in the first three pages of form 1) Front page form, 2) First half-semester form, and 3) Second half-semester form) is simultaneously added to a subject review form. This subject re-view form may then be exported to create a LDMap of the subject. For an effective curriculum review all core subjects need to be

IJEME, Vol. 3, No. 1, March 2019, 27-40. 
mapped and hence the collection of data from some form of compulsory tasks such as a Subject Information Sheet or lesson plan is needed.

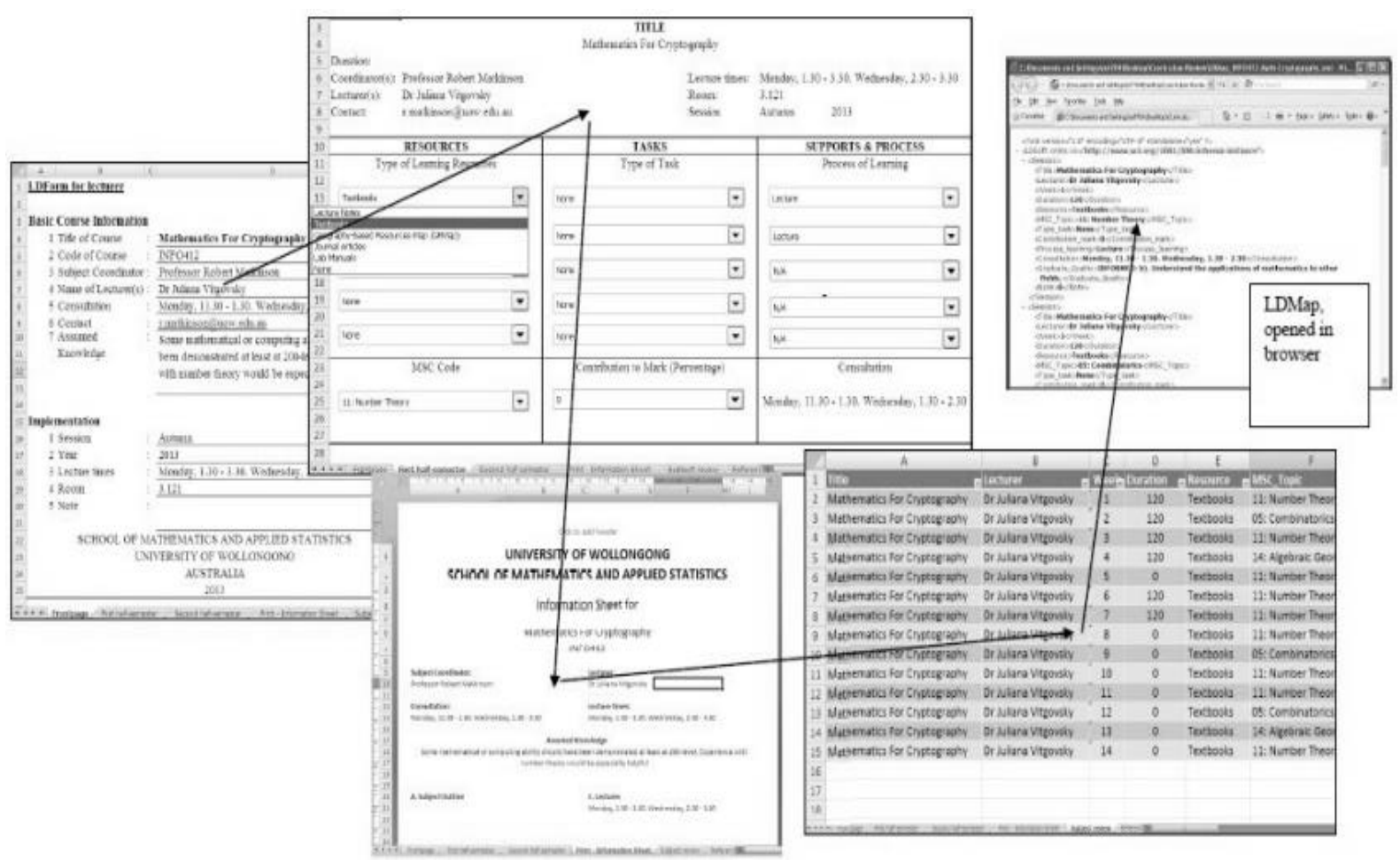

Figure 2. Automatic data flow between forms

The home section is the Frontpage of LDForm and this is used to collect general information about the subject. The learning design form can now be used to gather information that is provided in the Subject Information Sheet given to students at the commencement of each subject. Data not traditionally provided in subject information sheets, but included in the LDforms includes aligned resources, tasks, and supports and the process of learning for each meeting or lecture. In this way, the form as originally intended for the sharing of learning designs gathers data regarding the way the lecturer teaches the student about a particular subject. The learning design in this way is "recorded" and is also available for the curriculum review.

\section{Scenario for Use of LDMap in Curriculum Review}

Participations of lecturers in the review process is expected to disperse the process allowing the responsible coordinators or staff to easily and automatically conduct just the simple task of collating available LDMaps the review. As a result of the import, all the data from all LDMaps was inserted in the Learning Design Data worksheet.

The data contained in the LDMaps is automatically analyzed by the system, within the Learning Design-based Curriculum Reviewer (LDCR) tool. Currently, in accord with the LDMaps, five types of information are available as a result of the review. The categories of results are grouped within five sections: 1) Subject information, 2) Learning resources, 3) Topics taught as classified with the Mathematics Subjects Classification, 4) Distribution of graduate qualities, and 5) Evaluation. If this system is implemented for all subjects in the school or 
department then the results in overall will reflect the composition of topics or breakdown of graduate qualities addressed. The results can be used for school or department self-reflection or evaluation as part of mathematics curriculum review, based on the design of teaching and learning for each subject within this curriculum. In this demonstration, the results for each of the five sections are based on only two subjects.

The detailed information and function from each section are described in five sections. The first section is the Subject Information. This section displays a list of subjects and the expected process of teaching and learning (lecture, discussion, etc.) of each subject for all subjects provided by the curriculum. The second section is Teaching and Learning Methods. This section displays a list of the type of teaching method (discussion, lecture, workshop, presentation, etc.) used, available, and expected to be used by lecturer or teacher for all subjects provided by the curriculum. The third section is the Distribution of Mathematics Subject Classification. This section displays the distribution of mathematical subjects' classification of subjects provided by the curriculum. This information also reflects the school or department strength, for example, a higher percentage of subjects or most teachers or lecturers are in the field of Geometry, Algebra or other fields. In terms of the Mathematics Subject Classification, the item Mathematical Logic and Foundation counted for $32.14 \%$ of the content. This means that for these two example subjects, this classification item is dominated by the Mathematics Logic Foundation rather than other topics (see in Figure 3).

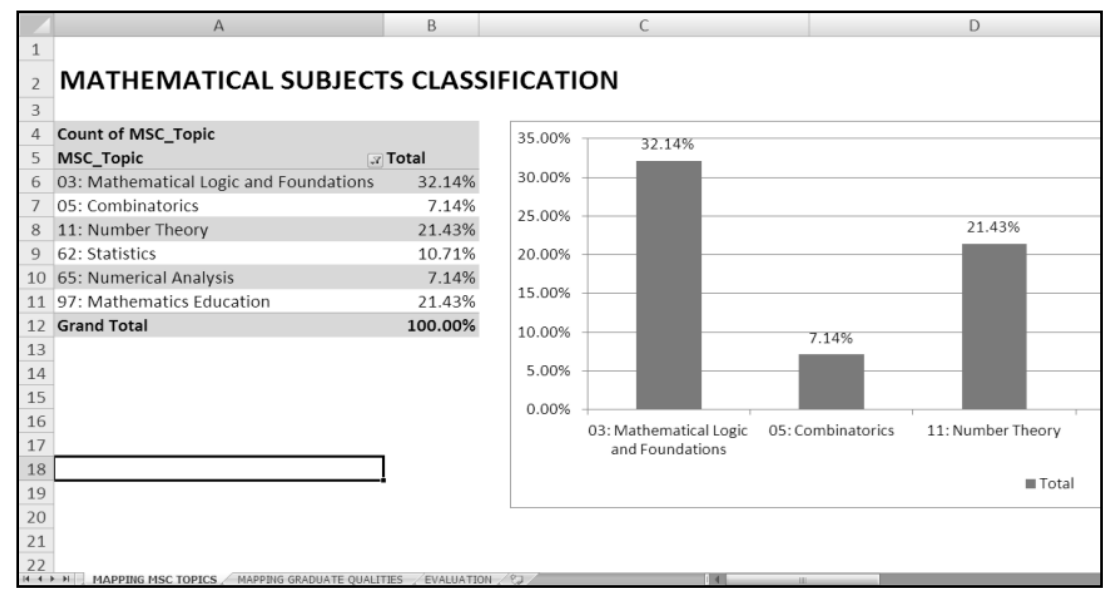

Figure 3. Review of topics using the Mathematical Subjects Classification

More specific classification, deeper levels, for example, subtopics for Mathematical Logic and Foundations (such as explicit machine computation and program, logic in the philosophy of science, general logic), also can be counted and visually displayed using graphics if this information were collected in the LDForm. The maximum number of subtopics to be displayed in the graphics depends on the MS Excel capability to show a number of columns in the spreadsheet.

Next Section is Distribution of Graduate Qualities. This section displays the distribution of the five graduate qualities expected through the implementation of the curriculum. For example, given the two subjects Discrete Mathematics (MATH121) and Mathematics for Primary Educators (MATH131), the results of a

IJEME, Vol. 3, No. 1, March 2019, 27-40. 
curriculum review as displayed in Figure 4 reveals that in the section Graduate Qualities, the item Informed: Have sound technical knowledge in mathematics at a level to enable informed contribution in the community is counted at $67.86 \%$ of total expected graduate qualities to be achieved through the implementation of current curriculum. It means that for these two sampled subjects, this graduate quality dominated the expected graduate qualities to be achieved through the implementation of these subjects, in the current curriculum.

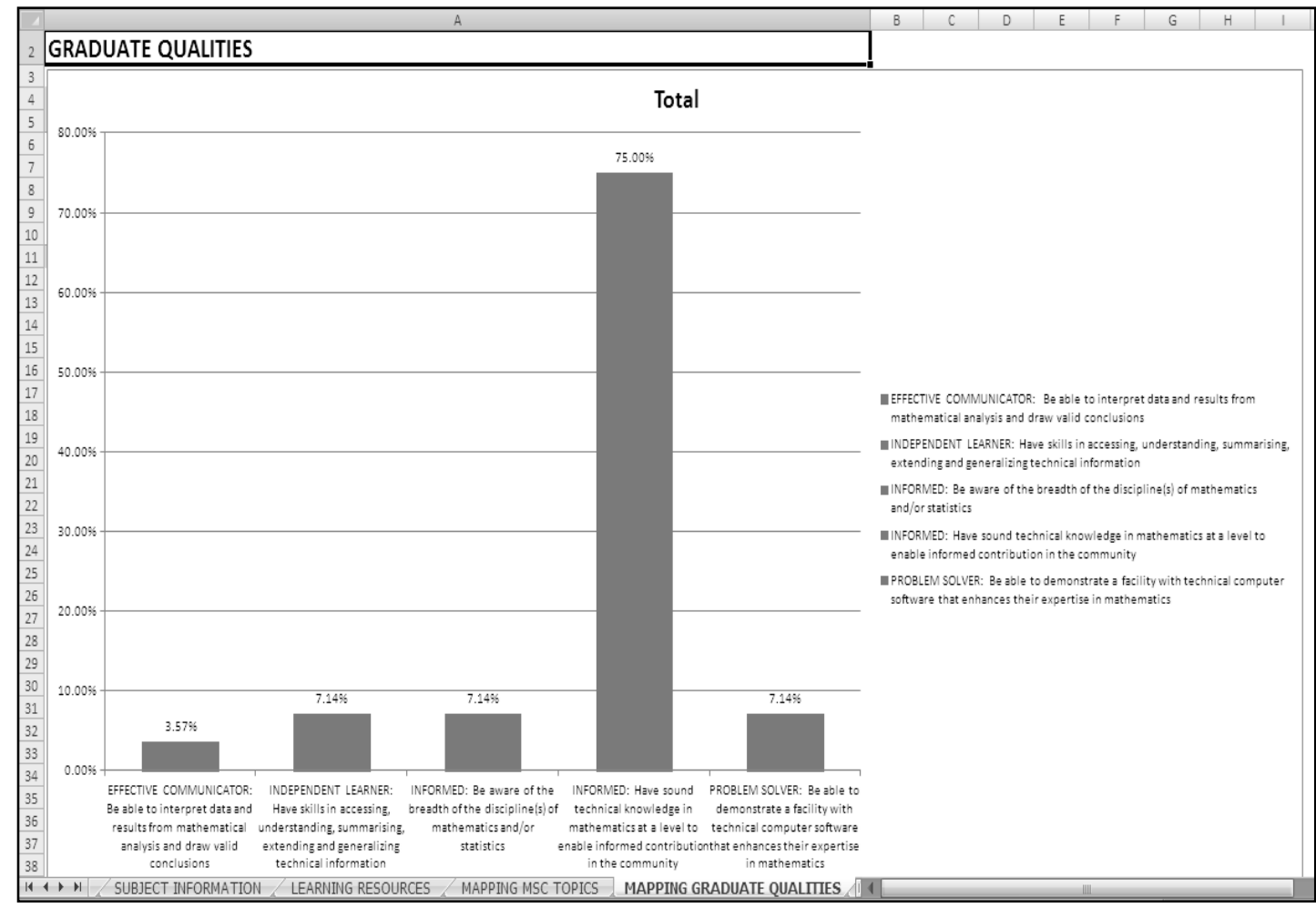

Figure 4. Mathematics Curriculum Review with regard to graduate qualities

As with the previous result (Mathematical Subjects Classification), the information displayed in this section depends on the data recorded using the LDForm. Institutions can set up in the LDForm the list of their expected graduate qualities including subcomponents of each attribute, for selection by lecturers. Then the Learning Design-based Curriculum Reviewer will aggregate the data and visually display the summaries.

The last section is the Evaluation (Assessment). This section displays the weekly scheduled within-session assessment and the percentage of the evaluation (or assessment) contributed by lecturers for each subject. The final examination or end of session assessment is not included. For example, evaluation is scheduled in week 7 and week 14, contributing 25, 30, and 40 percent (the data is aggregated for all subjects, with no individual subject identified). In week 7, two major assignments contributing $25 \%$ and $30 \%$, while for week 14 two major assignment worth of $40 \%$ are due.

Many other potential outputs can be revealed based on documented learning designs in LDMap using LDCR, for example comparing the process of learning (lecture, discussion, etc.) for each subject, and related weekly workload of each 
lecturer. The potential for outputs depends on information collected using LDForm, as the main function of the LDCR is to aggregate and analyze data and visually display it in the prepared form. New pages would need to be set up in EXCEL to automatically produce the required output for additional topics. All of these results may useful for the institution for self-reflection and/or evaluation in regard to mathematics curriculum

\section{Staffs Interview}

The participants in this activity were members of staff who were involved in either curriculum mapping or curriculum review at the University of Wollongong, Australia. The academics were selected using snowball sampling method, through the recommendation from one academic to the others based on their experiences and knowledge of who was engaged in curriculum mapping or automation of subject information sheets.

The participants were asked whether they are interested in providing comments regarding the improvement of the Learning Design Map (LDMap), Learning Design Form (LDForm), and Learning Design-based Curriculum Review (LDCR) applications developed for curriculum review during this research project or if they wished to demonstrate their own tools. The interviews related activities in this section are listed in Table 2.

Table 2. List of interview activities

\begin{tabular}{lll}
\hline No & People/Group & Activity \\
\hline 1 & $\begin{array}{l}\text { Professor } \\
\text { Robinson* } \\
\text { Professor Lucas * } \\
\text { Professor } \\
\text { Hamilton* } \\
\text { Mr. Andrew* }\end{array}$ & $\begin{array}{l}\text { Demonstration of LDMap, LDForm, and LDCR and } \\
\text { Discussion } \\
\text { Demonstration of Curriculum Mapping System and } \\
\text { discussion. Followed by trial from researcher to their } \\
\text { demo system and Discussion }\end{array}$ \\
3 & Dr. Richardson* & $\begin{array}{l}\text { Demonstration of LDMap, LDForm, and LDCR followed by } \\
\text { Interview and Discussion } \\
\text { Demonstration of LDMap, LDForm, and LDCR followed by } \\
\text { Interview and Discussion }\end{array}$ \\
\hline Dr. Pellace* & &
\end{tabular}

Interviewee 1 is an experienced academic in the field of curriculum mapping and review, and she is also a professor and head in this relevant field at the University of Wollongong. When the researcher demonstrated the analysis of LDMaps containing the learning designs data, with LDCR. There was raised discussion on the mismatch between subject descriptions in units (school or faculty) with the centralized university database. Over time these discrepancies lead to curriculum creep, as lecturers make minor changes to their subject descriptions.

The second interview provided practical information about how a curriculum mapping system could be implemented. The researcher's focus was on the use of LDMap to enable lecturers to document and share their own learning designs, and in this case, the subject outline is simply a template, one product of the process,

IJEME, Vol. 3, No. 1, March 2019, 27-40. 
which typically involves additional customization before finalization. This is also raised discussion on lecturers moving from one institution to another institution can still use their own learning designs documented in LDMap for review of their subjects. In the future, it is likely that for curriculum review, Web-based applications of LDCR, will be required to readily analyze LDMaps from all lecturers.

The third interview provided information from an experienced researcher in the area of learning designs. This lecturer is currently a learning designer at the University of Wollongong. The learning design should be visually displayed for ease of understanding and she concurred that resource data, tasks, and supports to show how teaching and learning to be conducted is important data to collect. She recognized that in practice it is rather difficult to manually create diagrams to represent learning designs and included in this the difficulty of displaying representations of learning designs in web-based applications or in browsers.

The fourth interview provided information from an experienced academic member of staff on the topic of curriculum review. After she saw the researcher's demonstration on how LDMaps can be analyzed using LDCR for use in curriculum review, Dr. Pellace while applauding the functionality of the LDMap provided advice about sustainability. One of her key concerns in relation to curriculum mapping is the identification of a group of people to manage the software and its products that is the data in the long term needs to be appropriately stored and accessible. From an organizational perspective, when lecturers are responsible for the maps they can be readily lost to the organization as people, for example, move to other positions. If the tools and data are to be sustained and maintained, written documentation with contact for support and help is required as is a person responsible for the data for implementation in curriculum reviews.

Usability is a key feature of this academic. Addressing issues with respect to improving usability, particularly in terms of enabling the modification of the forms for data collection and output were of key concern in this project.

\section{Future Implementation}

There are many schools of mathematics in the world. As indicated in the interviews each school may have different needs for conducting curriculum reviews. In order to improve the usability of the tool for use in curriculum review by other institutions or faculties, the tool, in particular, the LDForm, to some extent must be modifiable. The modifiability of the LDForm means that it is customizable by the educator, school or university for use in curriculum review for their own unit. The modifiability feature of LDForm is essential if this tool is to be made available and useful for many schools or universities in their activities of curriculum review.

The key in making successful modifications to the LDForm and LCDR is by keeping consistency (or equivalency) of LD Maps structure between the LDForm and LDCR. The equivalence between XML maps can be ensured by making the XML nodes both name and order on the LDForm the same as in LDCR. LDMap in this system functions as a "bridge" between LDForm and LDCR to enable learning design data captured using LDForm to be transferred to LDCR for use in curriculum review. The data from each LDForm is automatically placed in a section called Subject Review and from here it is exported to an LDMap. Ideally, these are collected together and stored in a dedicated folder. All these maps, generated to have the same nodes, in the same order are then imported to the LDCR section Learning Design Data. From this, the 
review is conducted with the automatic generation of the summaries for each node of data collected.

Another potential use is for mapping national curriculum in relation to mathematics. The latest version of Indonesian national curriculum, at the time of this research, is Curriculum Document year 2013 by the Ministry of National Education and Culture, Republic of Indonesia. The National curriculum in elementary schools is implemented through thematic teaching and learning, so the mathematics content is mixed with other subjects such as the Indonesian language and writing. On the other hand, the mathematics curriculum in senior high school is pre-dominantly for preparation of students to take the tertiary study at university or college levels. In some way, mapping of mathematics topics in secondary schools is important because students with solid mathematics background are better for engaging in mathematics learning (Matthews et.al, 2009). The role of mathematics topics, as mapped by Mathematics Subjects Classification should be carefully covered in the secondary schools' national curriculum.

These maps as they are based on XML technology can be transferred interplatform and operating system, collected and imported by the head of institutions to undertake a review of the total curriculum (or for sharing of maps). The illustration is shown in Figure 5.

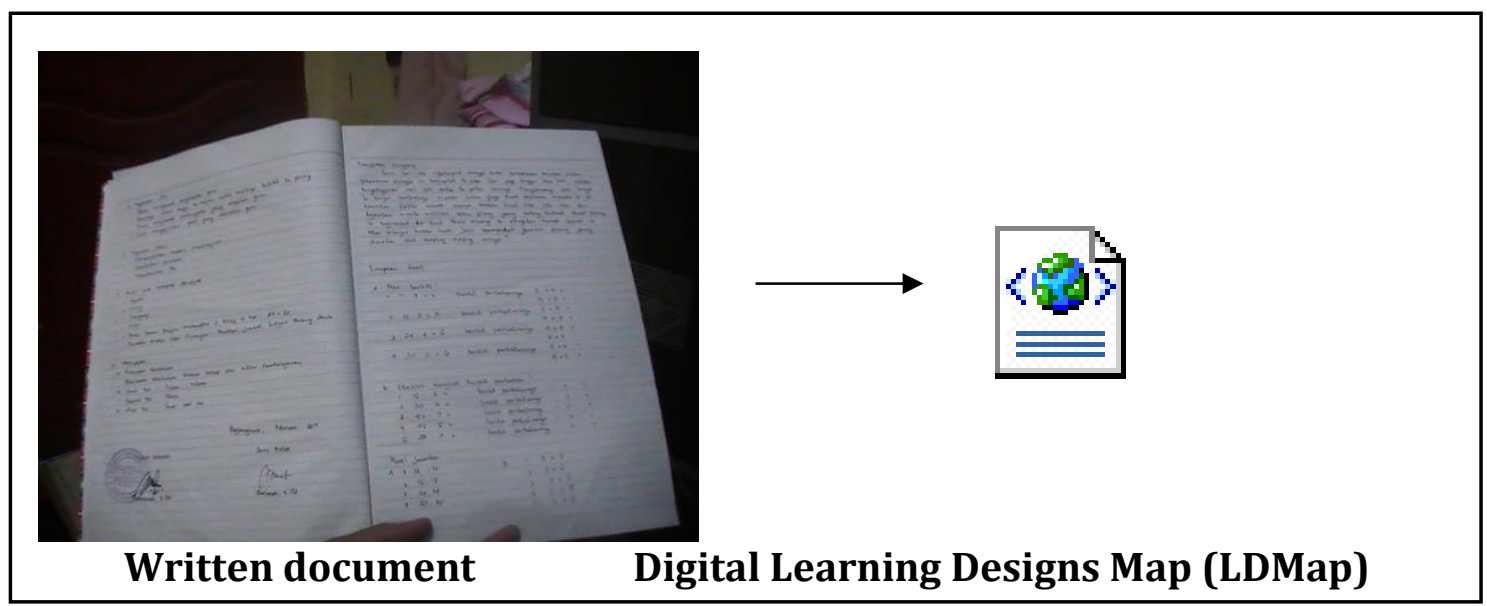

Figure 5. From written learning design to Learning Design Map

Further exploration and implementation by teachers as distinct from the researchers are required to know the practical implications of this technique demonstrating what is required for a curriculum review in higher education.

\section{CONCLUSION}

The available Learning Design Maps can be further advanced for use in curriculum review. Learning designs data can be extracted and aggregated for automated reporting of results in curriculum review. The process of mathematics curriculum review, as explained in this paper, can be facilitated using the Learning Design Map (LDMap) and Learning Design-based Curriculum Reviewer (LDCR). The automatic reporting of results of the curriculum review, in particular, the aggregated information of current mathematics subjects classifications and graduate qualities can then be used in institutional self-reflection.

IJEME, Vol. 3, No. 1, March 2019, 27-40. 


\section{REFERENCES}

Davis, E. (1981). Teachers as Curriculum Evaluators (Classroom and Curriculum in Australia). Sydney: George Allen \& Unwin Ltd.

Dressel, P.L. (1965). The need for curriculum review: courses, qualities, and costs. Journal of Higher Education 36(8), 443-448.

Fathurrohman, M., Porter, A., \& Worthy, A.L. (2012). Maps of Learning Designs for Teachers in Developing Countries to document and share mathematical teaching and learning experiences. Paper presented at 12th International Congress on Mathematical Education (ICME-12). Seoul, South Korea.

Hill, H.C., \& Charalambous, C.Y. (2012). Teacher knowledge, curriculum materials, and quality of instruction: Lesson learned and open issues. Journal of Curriculum Studies, 44(4), 559-576.

Kallick, B., \& Colosimo, J. (2009). Using Curriculum Mapping and Assessment Data to Improve Learning. Thousand Oaks, California: Corwin Press

Lee, P.Y. (2010). Designing a mathematics curriculum. Journal on Mathematics Education, 1(1), 1-10.

Matthews, K.E., Adams, P., \& Goos, M. (2009). Putting it into perspective: mathematics in the undergraduate science curriculum. International Journal of Mathematical Education in Science and Technology, 40(7), 891-902.

McKenney, S. (2008). Shaping computer-based support for curriculum developer. Computers \& Education, 50(1), 248-261.

Naseer, M.S. (2018). Impact of Professional Development Training Curriculum on Practicing Algebra Teachers. International Journal on Emerging Mathematics Education, 2(2), 187-202. http://dx.doi.org/10.12928/ijeme.v2i2.10055

Revina, S., \& Leung, F.K.S. (2018). Educational Borrowing and Mathematics Curriculum: Realistic Mathematics Education in the Dutch and Indonesian Primary Curriculum. International Journal on Emerging Mathematics Education, 2(1), 1-16. http://dx.doi.org/10.12928/ijeme.v2i1.8025

Ross, S.M., Morrison, G.R., Hannafin, R.D., Young, M., Akker, J., Kuiper, W., Richey, R.C., \& Klein, J.D. (2008). Research Designs. In J.M. Spector, M.D. Merrill, J.V. Merrienboer, and M.P. Driscoll (Eds), Handbook of Research on Educational Communications and Technology. New York, NY: Taylor \& Francis Group. 
IJEME, Vol. 3, No. 1, March 2019, 27-40. 